\title{
Facial-oropharyngeal Kaposi Sarcoma in a HIV-seropositive man
}

\author{
Yuji Hirai ${ }^{1-3}$, Toshio Yoshihara ${ }^{4}$, Toshiko Motoji ${ }^{2}$ and Kyoichi Totsuka ${ }^{1,2}$
}

Key words: HIV, AIDS, Kaposi sarcoma, facial edema, oropharyngeal

(Intern Med 51: 2989-2990, 2012)

(DOI: 10.2169/internalmedicine.51.8620)

A 26-year-old man with dysphagia and a swollen lymph node in the neck presented at the Department of Hematol-

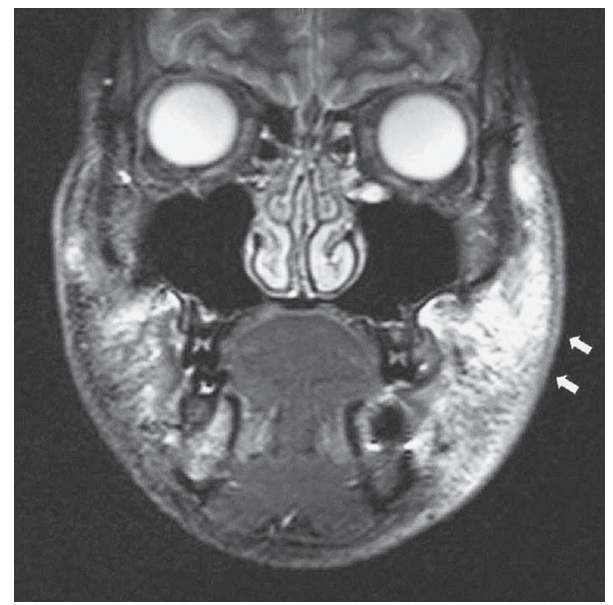

Picture 1. ogy. He also demonstrated cheek and facial edema with difficulty in opening his eyes. He was diagnosed to be seropositive for the human immunodeficiency virus (HIV) (CD4 $221 / \mu \mathrm{L}, \mathrm{HIV}-\mathrm{RNA}$ PCR $22,000 \mathrm{copy} / \mathrm{mL}$ ) at this time. Tumor lesions were found extending under the facial skin (Picture 1), neck lymph nodes and oropharynx on magnetic resonance imaging (MRI). His epiglottis was found to be compressed by a tumor using a nasal fiber scope (Picture 2). A lymph node biopsy revealed Kaposi sarcoma (KS). No opportunistic infections were found. Liposomal-doxorubicin (LD) was administered to prevent airway blockage due to $\mathrm{KS}$. His facial-oropharyngeal KS and facial edema both resolved completely after administering antiretroviral therapy (ART). Men are usually less likely than women to present with lesions of the face in such conditions (Men: Women= $15 \%: 32 \%$; (OR) 2.8, 95\%(CI) 1.4-5.7, p=0.005) (1). The rate of HIV-seropositive KS has decreased approximately 5fold since the introduction of ART (2).

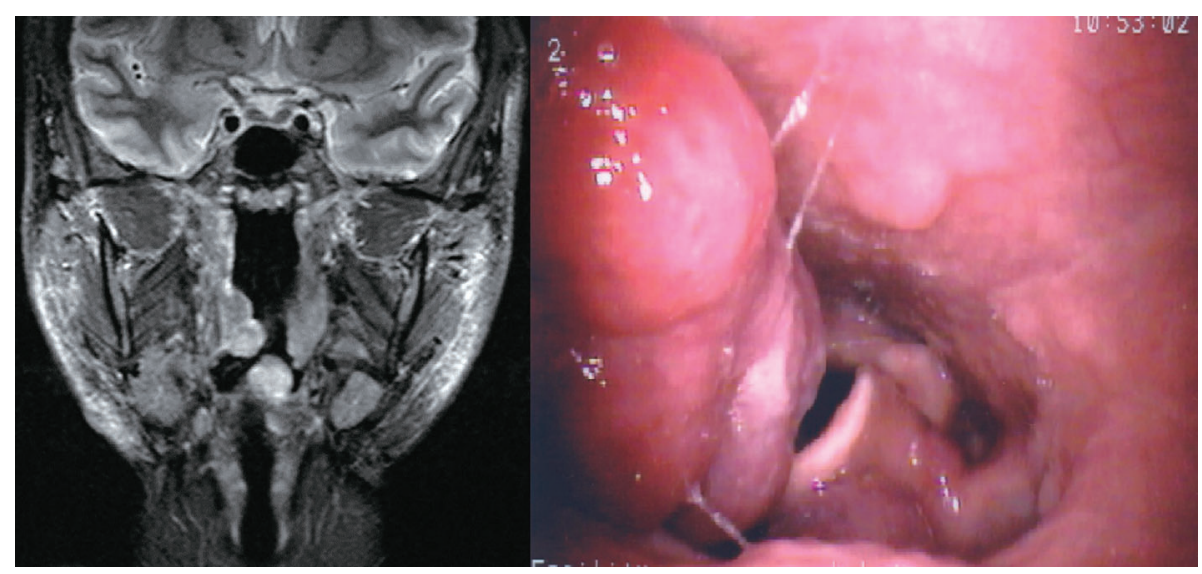

Picture 2.

\footnotetext{
${ }^{1}$ Department of Infectious Diseases, Tokyo Women's Medical University Hospital, Japan, ${ }^{2}$ Department of Hematology, Tokyo Women's Medical University Hospital, Japan, ${ }^{3}$ Internal Medicine, Tokyo Metropolitan Health and Medical Cooperation Tama-Hokubu Medical Center, Japan and ${ }^{4}$ Department of Otorhinolaryngology, Tokyo Women's Medical University Hospital, Japan Received for publication July 17, 2012; Accepted for publication July 24, 2012 Correspondence to Dr. Yuji Hirai, yuji-hirai@clabo.twmu.ac.jp
} 
The authors state that they have no Conflict of Interest (COI).

\section{References}

1. Phipps W, Ssewankambo F, Nguyen H, et al. Gender differences in clinical presentation and outcomes of epidemic Kaposi sarcoma in Uganda. PLoS One 5: e13936, 2010.

2. Shiels MS, Pfeiffer RM, Hall HI, et al. Proportions of Kaposi sarcoma, selected non-Hodgkin lymphomas, and cervical cancer in the United States occurring in persons with AIDS, 1980-2007. JAMA 305: 1450-1459, 2011. Erratum in: JAMA 306: 1548, 2011.

(C) 2012 The Japanese Society of Internal Medicine http://www.naika.or.jp/imonline/index.html 